\title{
Plasmonic Optical Fiber Sensors using Different Nanoparticles
}

\author{
Ranjit Singh \\ Department of Electronics \& Communication \\ Engineering, Shaheed Bhagat Singh State \\ Technical Campus Ferozepur 152004, Punjab, \\ India
}

\author{
Sanjeev Dewra \\ Department of Electronics \& Communication \\ Engineering, Shaheed Bhagat Singh State \\ Technical Campus Ferozepur 152004, Punjab, \\ India
}

\begin{abstract}
This paper present an investigation on Localized Surface Plasmon based optical fiber sensor and comparative performance of design with nanoparticles of different material on the tip of fiber. It is found that the Silver nanoparticles have higher sensitivity of $300 \mathrm{~nm} / \mathrm{RIU}$ and 10.7 figure of merit when refractive index of surrounding varies from 1.33 to 1.36 . Whereas the copper and aluminum has the sensitivity of $133 \mathrm{~nm}, 333 \mathrm{~nm}$, figure of merit of 2.7 and 8.1 respectively. It is also observed that the Surface Plasmon Resonance curve of silver nanoparticles has narrow width which improves the detection of accuracy as compared to copper and aluminum.
\end{abstract}

\section{Keywords}

Optical fiber sensor, nano-particles, refractive index, Surface Plasmon Resonance.

\section{INTRODUCTION}

With the event of glass fiber technology and communication technology, the optical fiber sensing technology has been replacing variety of detector. In which surface Plasmon resonance sensor take more attention because of less susceptible to external factors like light fluctuations, environment and so on. It has several advantages due to label free, high selectivity, high speed responsibility. In SPR technique, a TM (transverse magnetic) or p-polarized light causes the excitation of electron density oscillations (known as surface Plasmon wave, SPW) at the metal-dielectric interface. In optical fiber to excite SPR metal dielectric surface formed near to the core. Firstly a prism was used to excite the surface plasmons [1-9]. The prism-based SPR detector has many of disadvantages such as big in size and the existence of some optical and moving parts. In remote sensing application prism based SPR sensor cannot be applicable. To overcome this prism is replaced by optical fiber [10]. SPR probe can be miniaturized in optical fiber, which can be advantageous for samples which are available in small quantity or are costly. The motivating optical properties are determined by the localized and propagating surface Plasmon resonances (SPR). These Plasmonic resonances of the metal surfaces can be adapted by proper tuning of the physical and geometrical parameters of such structures $[11,12]$.Because of these benefits the surface Plasmon resonance-based optical fiber sensors have drawn a lot of attention [13-18].For LSPR sensor various type of metals like silver, copper and aluminium used at the surface near sensing layer to excite these waves. Pradeep Kumar Teotia et al [19] obtained high sensitivity using multilayer grating configuration. Peipei Jia et al [20] found that Sensitivity of SPR based sensor highly affected by changing the shapes and thickness of the metal.
In previous work, J. Gabriel Ortega Mendoza et al [21] used silver nano particles at the tip of fiber and sensitivity found to be $67.5 \mathrm{~nm} / \mathrm{RIU}$. To extend the work, new design of LSPR based optical fiber has been proposed, in which resonance sensitivity enhances to $330 \mathrm{~nm} / \mathrm{RIU}$ and $28 \mathrm{~nm}$ FWHM which increase FOM for better sensitivity of sensor.

\section{DESIGN AND SIMULATION METHOD}

Figure 1(a) depicts the 2D design of LSPR based optical fiber sensor modeled within OptiFDTD simulation by solving Maxwell equation. This is the FDTD method based simulator employed for determining the electromagnetic behavior of the design.

Plasmonic properties of the noble metal are used for detection in this proposed structure of optical fiber sensor. Plasmonic is the study and application of the interactions of opticalfrequency electromagnetic field oscillations with the free electrons in a metal, which behave like a charge-separated gas, or plasma. Nanoparticles of silver, copper and aluminum of size $100 \mathrm{~nm}$ are used at the tip of fiber to excite LSPR and detection plane used behind the Gaussian source input for comparative result of these different material. The observation plane $\mathrm{z}-\mathrm{x}$ is used to detect the excitation of LSPR. Bragg grating formed with in core by uniformly changing the refractive index from 1.46 to 1.48 as shown in design.

The relative permittivity $\mathrm{er}(\omega)$ of the different Nano-particles was determined using the multi-oscillator Lorentz-Drude model [22].

$$
\varepsilon_{r}(\omega)=\varepsilon_{\infty}+\sum_{m=0}^{M}\left(\frac{\mathrm{f}_{\mathrm{m}} \omega_{\mathrm{p}}^{2}}{\omega_{\mathrm{m}}^{2}-\omega^{2}+\mathrm{i} \omega \Gamma_{\mathrm{m}}}\right)
$$

Where

$\varepsilon \infty=$ Permittivity at infinite frequency

$\mathrm{fm}=$ Oscillator strengths

$\Gamma \mathrm{m}=$ Damping frequency

$\omega \mathrm{p}=$ Plasma frequency

$\omega=$ Incident wave frequency

$\omega \mathrm{m}=$ resonant frequency

The plasma frequency ( $\omega p$ ) used for the Silver 0.14 $\mathrm{x} 1017 \mathrm{rad} / \mathrm{sec}$, copper $0.164 \mathrm{x} 1017 \mathrm{rad} / \mathrm{sec}$ and aluminium $0.227 \mathrm{x} 1017 \mathrm{rad} / \mathrm{sec}$ respectively. The rest of the parameters for these metals are given in table1 [22]. The input wave is 
continuous and centred at $680 \mathrm{~nm}$ which is linearly polarized in y-direction and convolved with a Gaussian envelope function. The mesh size is to be small enough to catch the wave attenuation within the skin depth.

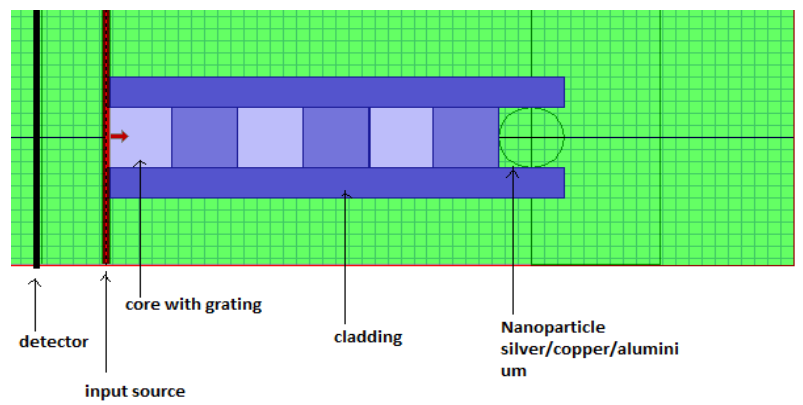

Fig.1 Design of SPR sensor with silver nanoparticles

\section{RESULT AND DISCUSSION}

The LSPR sensor response curve is plotted as relative power versus wavelength. When resonance occurs then at particular wavelength, a sharp dip reflected known as resonance wavelength. The position of dip is changing by varying the refractive index of surrounding. This change highly affects the parameters of SPR optical fiber sensor. For the most effective performance of the sensor, resonance sensitivity and figure of merit should be high. Sensitivity depends upon the change in resonance wavelength when refractive index (ns) of surrounding varies as given in equation (5).

$\mathrm{Sn}=(\Delta \lambda \mathrm{res}) /(\Delta \mathrm{ns})$

$\Delta \lambda$ res $=$ change in Resonance wavelength

$\Delta \mathrm{ns}=$ change in Refractive index of surrounding

A figure of merit (FOM) is presented to calculate and measure the sensing capability of the Plasmonic sensor. Formally, FOM is a dimensionless quantity that counts the effects of line width or FWHM $(\Gamma)$ and the shift in the resonance wavelengths. It is often calculated as equation 6 .

$$
\mathrm{FOM}=\mathrm{Sn} / \Gamma \text {. }
$$

After modeling and simulating the Plasmonic structure of optical fiber sensor, performance parameter is numerically analyzed using nano particles of different materials such as copper, silver and aluminum as shown in figure 2,3 and 4 respectively. Resonance Sensitivity for the proposed structure with copper is $133 \mathrm{~nm} / \mathrm{RIU}$, with aluminum is $333 \mathrm{~nm} / \mathrm{RIU}$, and with silver is $300 \mathrm{~nm} / \mathrm{RIU}$ on varying refractive index from 1.33 to 1.36 .

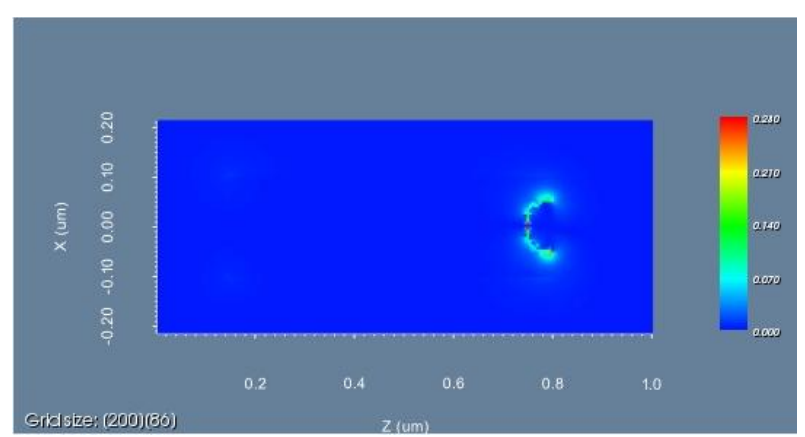

(a)

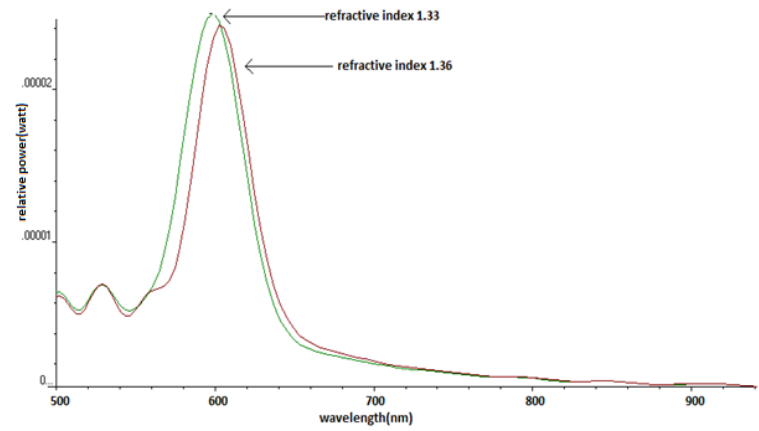

(b)

Fig 2. Excitation of LSPR in $x-z$ plane with copper in fig (a), Reflectance of LSPR sensor at refractive index 1.33 and 1.36 using copper nanoparticles in fig (b)

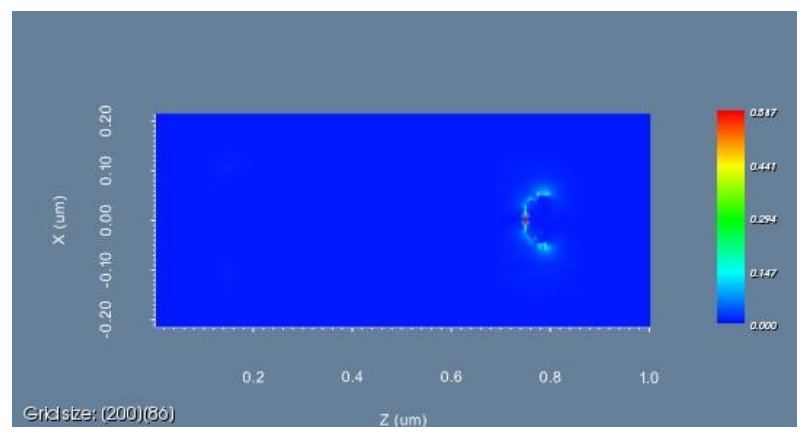

(a)

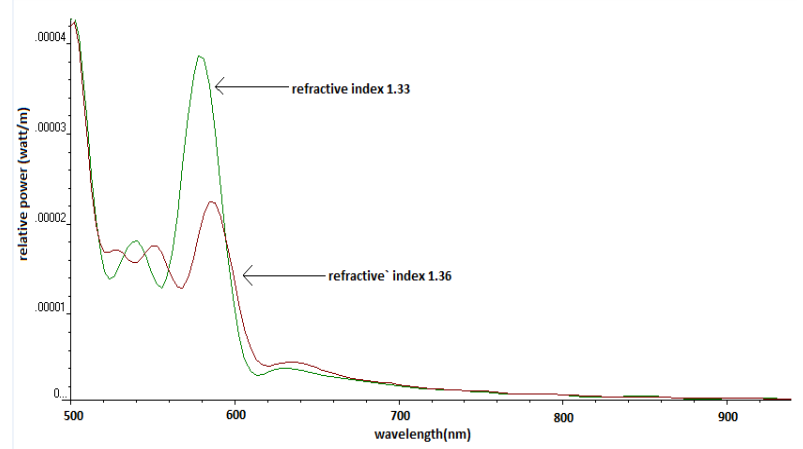

(b)

Fig 3. Excitation of LSPR in $x-z$ plane with silver in fig (a), Reflectance of LSPR sensor at refractive index 1.33 and 1.36 using silver nanoparticles in fig (b)

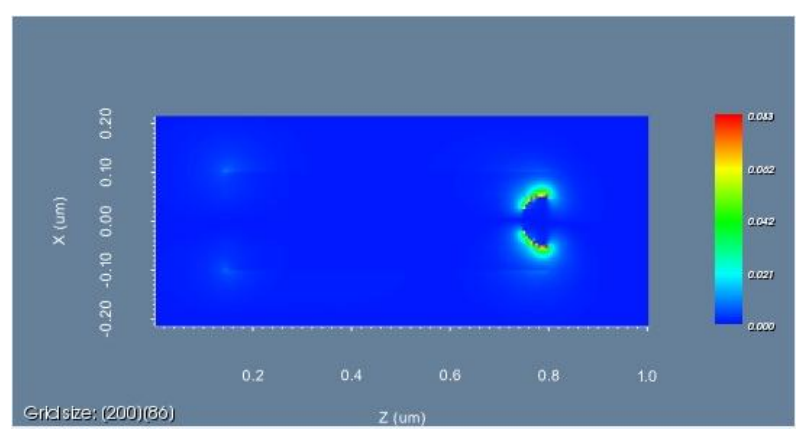

(a) 


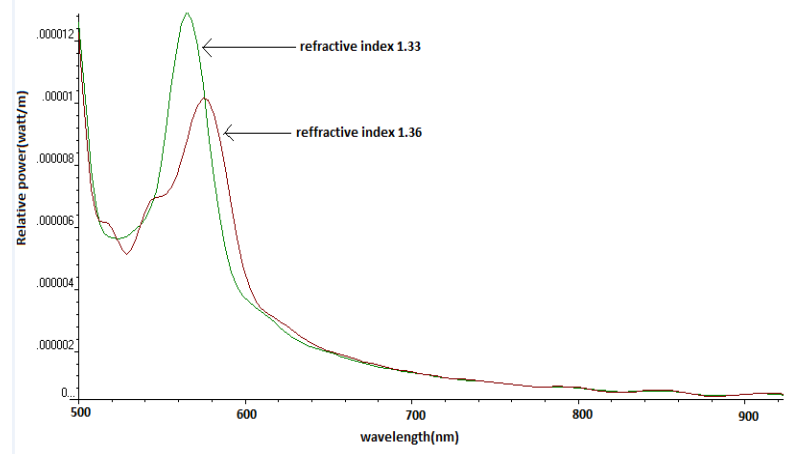

Fig 4. Excitation of LSPR in $x-z$ plane with aluminum in fig (a), Reflectance of LSPR sensor at refractive index 1.33 and 1.36 using aluminum nanoparticles in fig (b)

Comparison for different materials is as shown in fig 5.From the observation, it is concluded that silver has lowest value of FWHM that is $28 \mathrm{~nm}$ and better FOM as compared to copper and aluminum as shown in table 2. LSPR sensor using silver particles having sensitivity of $300 \mathrm{~nm} / \mathrm{RIU}$ which is comparatively better than the previous work [19].

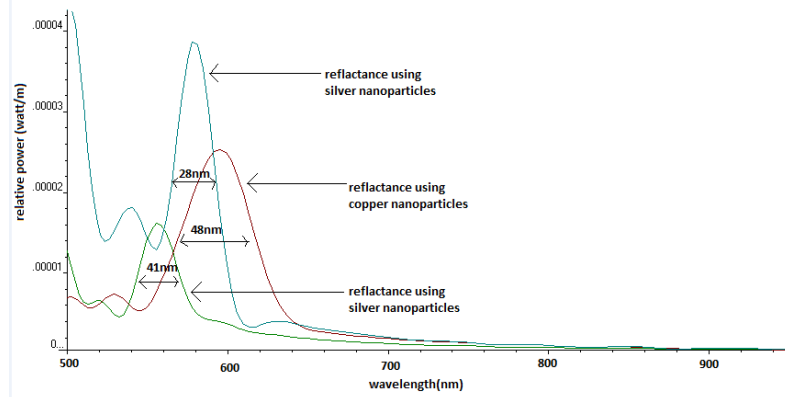

Fig. 5 Comparison of FWHM using copper, silver and aluminum nanoparticles.

Table 1. Plasmonic parameters for different material

\begin{tabular}{|l|l|l|l|l|l|}
\hline \multicolumn{2}{|l}{ Material } & $\begin{array}{l}\text { Strength } \\
\left(\mathrm{f}_{\mathrm{m}}\right)\end{array}$ & $\begin{array}{l}\text { Resonant frequency } \\
\left(\omega_{\mathrm{m}}\right)\end{array}$ & $\begin{array}{l}\text { Plasma frequency } \\
\left(\omega_{\mathrm{p}}\right)\end{array}$ & $\begin{array}{l}\text { Damping frequency } \\
\left(\Gamma_{\mathrm{m}}\right)\end{array}$ \\
\hline \multirow{4}{*}{ silver } & Term 0 & 0.8450 & 0.00000 & $0.14 \times 10^{17}$ & $0.729 \times 10^{14}$ \\
& Term 1 & 0.0650 & $0.123 \times 10^{16}$ & $0.14 \times 10^{17}$ & $0.590 \times 10^{16}$ \\
& Term 2 & 0.1240 & $0.680 \times 10^{16}$ & $0.14 \times 10^{17}$ & $0.686 \times 10^{15}$ \\
\hline \multirow{4}{*}{ copper } & Term 0 & 0.5750 & 0.00000 & $0.164 \times 10^{17}$ & $0.455 \times 10^{14}$ \\
& Term 1 & 0.0610 & $0.444 \times 10^{15}$ & $0.164 \times 10^{17}$ & $0.574 \times 10^{15}$ \\
\cline { 2 - 6 } & Term 2 & 0.1040 & $0.449 \times 10^{16}$ & $0.164 \times 10^{17}$ & $0.160 \times 10^{16}$ \\
\hline \multirow{3}{*}{ aluminium } & Term 0 & 0.5230 & 0.00000 & $0.227 \times 10^{17}$ & $0.714 \times 10^{14}$ \\
\cline { 2 - 6 } & Term 1 & 0.2270 & $0.246 \times 10^{15}$ & $0.227 \times 10^{17}$ & $0.505 \times 10^{15}$ \\
\cline { 2 - 6 } & Term 2 & 0.0500 & $0.234 \times 10^{16}$ & $0.227 \times 10^{17}$ & $0.474 \times 10^{15}$ \\
\hline
\end{tabular}

Table 2. Evaluation parameters of localized surface Plasmon based sensor with different material

\begin{tabular}{|l|l|l|l|l|l|l|l|}
\hline $\begin{array}{l}\text { material of } \\
\text { nano particles }\end{array}$ & $\begin{array}{l}\text { Resonance } \\
\text { wavelengh at } \\
\text { refractive } \\
\text { index } 1.33\end{array}$ & $\begin{array}{l}\text { Resonance } \\
\text { wavelength at } \\
\text { refractive } \\
\text { index } 1.36\end{array}$ & $\begin{array}{l}\text { Change in } \\
\text { refractive } \\
\text { index }(\Delta \mathrm{n})\end{array}$ & $\begin{array}{l}\text { Change in } \\
\text { resonance } \\
\text { wavelength } \\
\left(\Delta \lambda_{\text {res })}\right.\end{array}$ & $\begin{array}{l}\text { Sensitivity } \\
\frac{\Delta \text { res }}{\Delta n \mathrm{~s}}\end{array}$ & FWHM & FOM \\
\hline Aluminum & $564 \mathrm{~nm}$ & $574 \mathrm{~nm}$ & 0.03 & $10 \mathrm{~nm}$ & $333 \mathrm{~nm} / \mathrm{RIU}$ & $41 \mathrm{~nm}$ & 8.1 \\
\hline Copper & $598 \mathrm{~nm}$ & $602 \mathrm{~nm}$ & 0.03 & $4 \mathrm{~nm}$ & $133 \mathrm{~nm} / \mathrm{RIU}$ & $48 \mathrm{~nm}$ & 2.7 \\
\hline Silver & $578 \mathrm{~nm}$ & $587 \mathrm{~nm}$ & 0.03 & $9 \mathrm{~nm}$ & $300 \mathrm{~nm} / \mathrm{RIU}$ & $28 \mathrm{~nm}$ & 10.7 \\
\hline
\end{tabular}

\section{CONCLUSION}

In this presented work, we analyzed parameters for LSPR based optical fiber sensor on three different nanoparticles. SPR sensor with higher sensitivity and figure of merit proposed for the future design. Design using fiber Bragg grating inscribed with in core and silver nanoparticles exhibits refractive index sensitivity of 300nm/RIU, 28nm FWHM and FOM of 10.7 which gives better performance than copper and aluminum. It is concluded that silver is better for design of LSPR sensor using grating within core than copper and aluminum in terms of refractive index sensitivity and figure of merit. There is also a scope to improve the detection limit by changing size and shape of the nanoparticles.

\section{REFERENCES}

[1] Singh R., Dewra S. and Rani A. 2016 Review on Performance of Optical Sensor based on different Nano particles in fiber. International Journal of Computer Science and Network.pp 102-107.
[2] Gent J. v., Lambeck P. V. and Kreuwel H. J. M. 1990 Optimization of a chemooptical surface plasmon resonancebased sensor. Applied Optics. vol. 29. pp. 2843-2849.

[3] Stenberg E., Persson B., Roos H., and Urbaniczky C. 1991.Quantitative determination of surface concentration of protein with surface plasmon resonance using radiolabeled proteins.Journal of Colloid and Interface Science.vol. 143.no. 2.pp. 513-526.

[4] Dougherty G. 1993.A compact optoelectronic instrument with a disposable sensor based on surface plasmon resonance. Measurement Science and Technology. vol. 4.no. 6. pp. 697-699.

[5] Ekgasit S., Tangcharoenbumrungsuk A., Yu F., Baba A., and Knoll W.2005.Resonance shifts in SPR curves of nonabsorbing.weakly absorbing, and strongly absorbing dielectrics.Sensors and Actuators B.vol. 105.no. 2.pp. 532-541. 
[6] Chyou J.-J., Chu C.-S., Chien F.-C., et al. 2006.Precise determination of the dielectric constant and thickness of a nanolayer by use of surface plasmon resonance sensing and multiexperiment linear data analysis.Applied Optics.vol. 45.no. 23. pp.6038-6044.

[7] Chiang H. P., Chen C.-W., Wu J. J., et al. 2007.Effects of temperature on the surface plasmon resonance at a metalsemiconductor interface.Thin Solid Films.vol. 515. no. 17. pp. 6953-6961.

[8] Person J. L., Colas F., Compere C., et al. 2008.Surface plasmon resonance in chalcogenide glass-based optical system. Sensors and Actuators B. vol. 130. no. 2. pp. 771-776.

[9] Feng W., Shenye L., Xiaoshi P., Zhuangqi C., and Yongkun D.2008.Reflective-type configuration for monitoring the photobleaching procedure based on surface plasmon resonance. Journal of Optics A. vol. 10. no. 9. Article ID 095102.

[10] Jorgenson, R.C.; Yee, S.S.1993.A fiber-optics chemical sensor based on surface Plasmon resonance. Sens Actuators B (1993).12.213-220.

[11] Ashry I, Elrashidi A, Tharwat MM, Xu Y, Mahros AM, 2015 . Investigating the optical transmission spectra of plasmonic spherical nano-hole arrays.Plasmonics 10:511-517.

[12] Mahros AM, Tharwat MM, 2015.Investigating the fabrication imperfection ofplasmonic nano-hole arrays and its effect on the optical transmission spectra.J Nanomater (2015):178583.

[13] Jorgenson R. C. and Yee S. S., 1993. A fiber-optic chemical sensor based on surface plasmon resonance.Sensors and Actuators B.vol. 12.no. 3.pp. 213-220.

[14] Harris R. D. and Wilkinson J. S., 2000. Waveguide surface plasmon resonance sensors.Sensors and Actuators B. vol. 29. no. 1-3. pp. 261-267.
[15] Lin W. B., Jaffrezic-Renault N., Gagnaire A., and Gagnaire H., 2000.The effects of polarization of the incident light-modeling and analysis of a SPR multimode optical fiber sensor. Sensors and Actuators A. vol. 84. no. 3. pp. 198-204.

[16] Slav'1k R., Homola J., Ctyrok'y J., and Brynda E., 2001. Novel spectral fiber optic sensor based on surface plasmon resonance. Sensors and Actuators B. vol. 74. no. 1-3. pp. 106-111.

[17] Piliarik M., Homola J., Man'1kov'a Z., and Ctyrok'y J.,2003 .Surface plasmon resonance sensor based on a single-mode polarization-maintaining optical fiber.Sensors and Actuators B.vol. 90. no. 1-3. pp. 236242 .

[18] Gentleman D. J., Obando L. A., Masson J.-F., Holloway J. R., and Booksh K. S., 2004.Calibration of fiber optic based surface plasmon resonance sensors in aqueous systems.Analytica Chimica Acta.vol. 515. no. 2. pp. 291-302.

[19] Teotia P. K., Kaler R.S., 2016. Multilayer with periodic grating based high performance SPR waveguide sensor. Optics Communications (2016).

[20] Jia, P., Yang, J. , 2015 Universal sensitivity of propagating surface plasmon resonance in nanostructure arrays. Opt. Express, 23, 18658-18664.

[21] Ortega-Mendoza J. G. , Padilla-Vivanco A. , ToxquiQuitl C. , Zaca- Morán P. , Villegas Hernández D. and Chávez F.,2014.Optical Fiber Sensor Based on Localized Surface Plasmon Resonance Using Silver Nanoparticles Photodeposited on the Optical Fiber End.Sensors, 14.18701-18710.

[22] Rakić A.D., Djurišić A.B., Elazar J.M. and Majewski M.L. 1998. Optical properties of metallic films for vertical-cavity optoelectronic devices. Appl Opt 37:5272-5283. 